\title{
Study of the Isothermal Curing of an Epoxy Prepreg by Near-Infrared Spectroscopy
}

\author{
Qian Wang, Birgit K. Storm, Lars P. Houmøller \\ Aalborg University Esbjerg, Niels Bohrs Vej 8, DK-6700, Esbjerg, Denmark
}

Received 12 November 2001; accepted 23 May 2002

\begin{abstract}
The commercial epoxy prepreg SPX 8800, containing diglycidyl ether of bisphenol A, dicyanodiamide, diuron, and reinforcing glass fibers, was isothermally cured at different temperatures from 75 to $110^{\circ} \mathrm{C}$ and monitored via in situ near-infrared Fourier transform spectroscopy. Two cure conditions were investigated: curing the epoxy prepreg directly (condition 1) and curing the epoxy prepreg between two glass plates (condition 2). Under both curing conditions, the epoxy group could not reach $100 \%$ conversion with curing at low temperatures $\left(75-80^{\circ} \mathrm{C}\right)$ for $24 \mathrm{~h}$. A comparison of the changes in the epoxy, primary amine, and hydroxyl groups during the curing showed that the samples cured under condition 2 had lower initial epoxy conversion
\end{abstract}

rates than those cured under condition 1 and that more primary amine-epoxy addition occurred under condition 2 . In addition, the activation energy under cure condition 2 $(104-97 \mathrm{~kJ} / \mathrm{mol})$ was higher than that under condition 1 $(93-86 \mathrm{~kJ} / \mathrm{mol})$, but a lower glass-transition temperature of the cured samples was observed via differential scanning calorimetry. The moisture in the prepreg was assumed to account for the different reaction kinetics observed and to have led to different reaction mechanisms. (c) 2003 Wiley Periodicals, Inc. J Appl Polym Sci 87: 2295-2305, 2003

Key words: activation energy; differential scanning calorimetry (DSC); glass transition

\section{INTRODUCTION}

Diglycidyl ether of bisphenol A (DGEBA)-based epoxy resins cured with dicyanodiamide (DICY) in the presence of an aryl-substituted urea (uron) accelerator have been widely used in industry, especially in the preparation of prepregs and adhesive coatings. Generally, the curing mechanism involves epoxy-amine addition and epoxy homopolymerization (or etherification) in the presence of a tertiary amine catalyst. Both of the two reactions proceed through a trimolecular mechanism, as shown in Scheme $1 .{ }^{1-3}$ The proton-donor group (water, alcohol, and hydroxyl group) influences both reactions. For the epoxy system containing the DICY hardener, in a study of the model system DGEBA/DICY/BDMA (benzyldimethylamine), Zahir ${ }^{4}$ reported that DICY acted as a latent cyanamide donor. The uron accelerator dissociates into dimethyl amine and reacts with epoxy to generate a tertiary amine that catalyzes the epoxy-amine addition and epoxy homopolymerization (Scheme 2). ${ }^{5-7}$ Both the DICY hardener and the uron accelerator are solids in the starting reaction mixture. Therefore, the reaction kinetics depend not only on the initial concentrations of the different components but also on the reaction temperature. ${ }^{8-10}$ The reported activation en-

Correspondence to: Q. Wang (qwang@aue.auc.dk).

Contract grant sponsor: Vestas A/S.

Journal of Applied Polymer Science, Vol. 87, 2295-2305 (2003) (C) 2003 Wiley Periodicals, Inc. ergies [from differential scanning calorimetry (DSC)] vary from 95 to $51 \mathrm{~kJ} / \mathrm{mol}^{9}$ The cure temperature and the ratio of different functional groups also influence the crosslinking density and the glass-transition temperature $\left(T_{g}\right)$ of cured epoxy resins. ${ }^{11,12}$ Although many studies have been made of this complicated system, ${ }^{13,14}$ a clear understanding of the curing mechanism has still not been achieved, and only a few studies have been reported on commercial products containing glass-fiber reinforcements. ${ }^{15,16}$

Near-infrared (NIR) spectroscopy has recently been proven to be a very useful technique for the study of epoxy resin curing. ${ }^{17-23}$ The major functional groups involved in the curing process-epoxy, primary and secondary amine, and hydroxyl functional groupscan be isolated well from the neighboring absorptions in the NIR spectrum, and this makes it possible to study the kinetics of the epoxy curing process. ${ }^{24-28}$ Another advantage of NIR lies in the fact that the absorptions of the functional groups are much lower than those in the Fourier transform infrared (FTIR) range; therefore, a relatively large quantity of samples and thicker samples can be studied, and cheap accessories such as glass plates and vials can be used instead of $\mathrm{KBr}, \mathrm{NaCl}$, and expensive inorganic crystal windows. NIR studies on the kinetics and mechanism of the epoxy curing process have been performed for several systems, which span from simple model systems with one epoxy functional group and simple primary and secondary amines to bifunctional, trifunctional, and tetrafunctional epoxy and amine sys- 


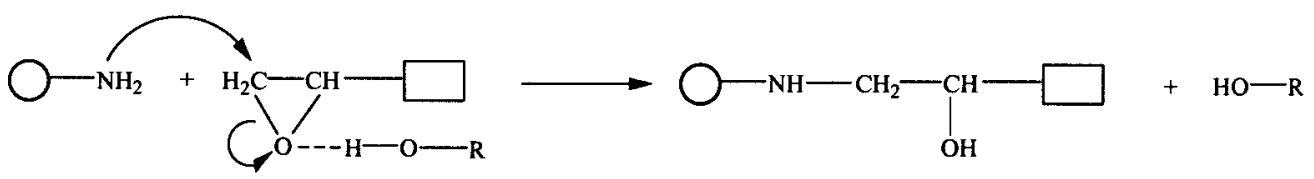

Epoxy-amine addition reaction

Initiation
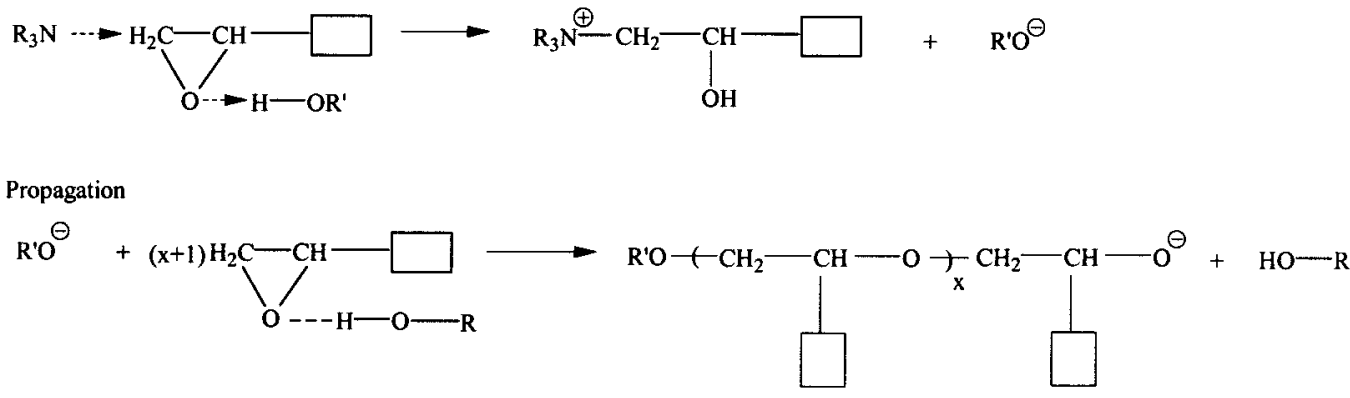

Epoxy homopolymerization or etherification

Scheme 1 Proposed models for the epoxy cure reactions.

tems. Most of the epoxy-amine combination systems studied are homogeneous solutions at the cure temperature, and the epoxy-amine molar ratios are close to 1 , amine-epoxy addition being the main reaction in the cure process. Both epoxy and amine group absorptions are well isolated and have strong absorption intensities in the NIR range. Quantitative NIR studies on heterogeneous epoxy systems are infrequent. Scattering effects may arise from the heterogeneity and result in erroneous quantification. Poisson et al. ${ }^{29}$ published their work on an NIR study of a DGEBA-based resin containing a DICY hardener and a diuron accelerator; the latter two components were fine powders dispersed in the resin. The results of their study showed that the molar extinction coefficients of the epoxy groups for different epoxy-containing compounds were the same. The change in the epoxy resin from liquid to solid and small changes in the sample thickness did not cause any significant changes in the spectrum, and they found that the kinetic data obtained by NIR agreed well with the results of size exclusion chromatography. However, in reported NIR studies of the curing of DGEBA/DICY/diuron complex systems, only the changes in epoxy functional groups were investigated, and an NIR study on this epoxy system reinforced with glass fibers has not been reported.

This article presents an in situ NIR study on the isothermal curing of the epoxy prepreg SPX 8800 at different temperatures under two cure conditions: curing the epoxy prepreg directly (condition 1) and curing the epoxy prepreg between two glass plates (condition 2). Because the epoxy prepreg reinforced with glass fibers was self-supportable, the prepreg was then placed in an NIR light path directly (condition 1). Because of the heating, a small amount of the epoxy resin flowed down at the edge of the sample during the early stage of curing, although it seems this flowing down had no significant effect on the curing kinetics. For comparison, the epoxy prepreg was placed between two glass plates to reduce any flowing of the reactants during curing (condition 2). With the NIR spectrum, besides the epoxy group, the changes in the hydroxyl and primary amine groups and absorbed water were also studied. In addition, DSC and FTIR measurements were taken of the cured epoxy prepreg so that we could compare the differences in $T_{g}$ and the other functional groups in the sample cured at different temperatures and conditions.

\section{EXPERIMENTAL}

\section{Materials}

The epoxy prepreg SPX 8800 is a commercial product from SP Systems (Newport, United Kingdom); it was used as received. It is a one-formulation prepreg that contains a DGEBA-based epoxy prepolymer, a DICY hardener, and a diuron accelerator. These three components constitute approximately $45 \mathrm{wt} \%$ of the prepreg, and glass fibers (55 wt \%) constructed in triaxial layers serve as the reinforcements. The chemical structures of the three components are shown in Scheme 3 .

\section{Techniques}

NIR spectroscopy was performed with a Bomem FT-NIR spectrometer equipped with an InAs detec- 


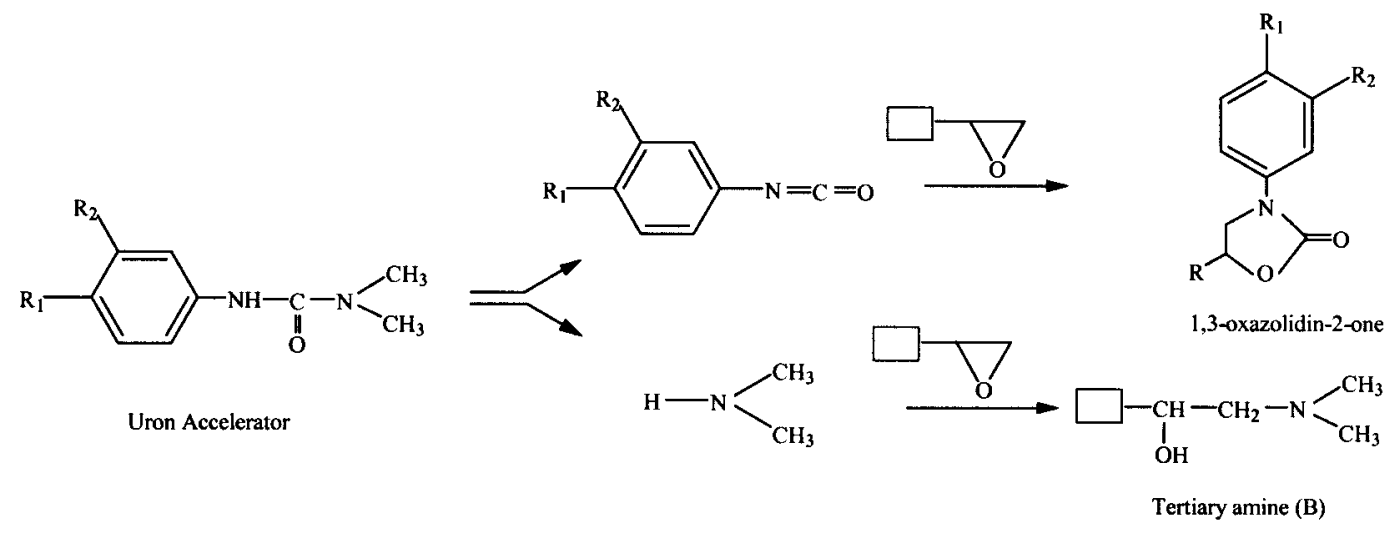

(a)

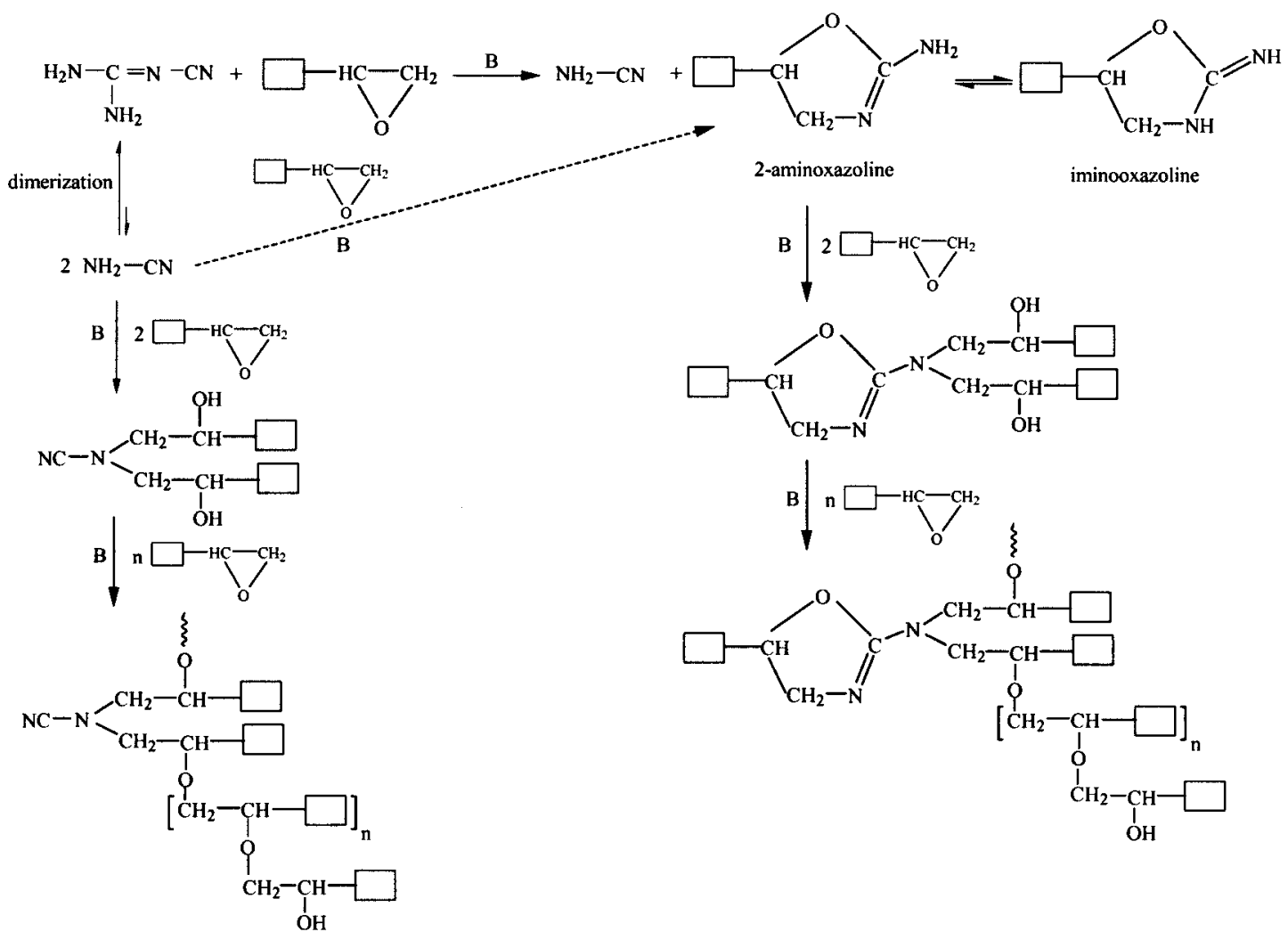

(b)

Scheme 2 Reactions of the DGEBA/DICY/uron system: (a) uron decomposition and tertiary amine (B) formation and (b) DICY acting as a latent cyanimide donor.

tor (Québec, Canada). One layer of the epoxy prepreg was put into a standard glass vial, which was then placed in a heating cell connected to a Hoval Omega CN76000 temperature controller (Québec, Canada) (cure condition 1). In another experimental setup, one layer of the prepreg was placed between two glass plates in a heating cell (cure condition 2). The isothermal curing of the epoxy prepreg was carried out in the heating cell.
During the curing of the prepreg, transmittance spectra were taken at defined time intervals. The wave-number range was $3800-9000 \mathrm{~cm}^{-1}$ with a resolution of $4 \mathrm{~cm}^{-1}$, and 32 scans were coadded to each spectrum. The background spectrum was taken on the empty glass vial or two glass plates equilibrated at the cure temperature. The transmittance of the sample was monitored by the align utility during the curing. 


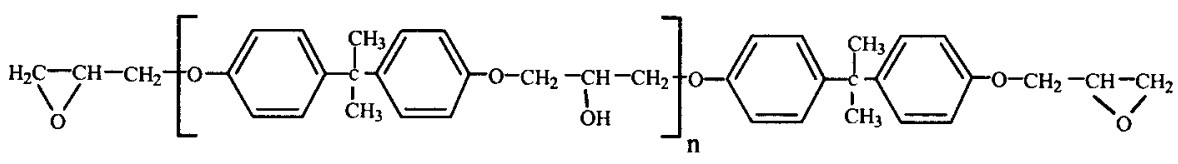

Diglycidyl ether of bisphenol A (DGEBA)<smiles>N#CN=C(N)N</smiles>

Dicyandiamide (DICY)<smiles>CN(C)C(=O)Nc1ccc(Cl)c(Cl)c1</smiles>

Diuron (N, N-dimethyl-N'-(3,4-dichloro)phenylurea)

Scheme 3 Structures of the chemical components in the epoxy prepreg.

FTIR spectra were taken on a Perkin Elmer Paragon 1000 (Llantrisant, United Kingdom) spectrometer. Powder was scratched from the cured sample and ground with $\mathrm{KBr}$ to make a tablet for transmittance scanning. For each spectrum, four scans were coadded at a resolution of $4 \mathrm{~cm}^{-1}$.

A DSC analysis of the cured prepreg was performed on a Mettler Toledo DSC $822^{\mathrm{e}}$ module (Schwerzenbach, Switzerland) equipped with a TSO 801RO universal sample robot autosampler; the Stare software system was used to program and control the DSC analysis and curve evaluation. The cured epoxy prepreg was cut into piece of about $20-27 \mathrm{mg}$ and put into a standard $40 \mu \mathrm{L}$ aluminum pan. The sample was heated to $230^{\circ} \mathrm{C}$ in the first run, quenched to $25^{\circ} \mathrm{C}$, and heated to $300^{\circ} \mathrm{C}$ in the second run. Both heating processes took place in an air atmosphere, and a ramp of $10^{\circ} \mathrm{C} / \mathrm{min}$ was used.

\section{Peak assignments}

Figure 1 shows the NIR spectra of the epoxy prepreg and DGEBA (molecular weight $=340$ ). A comparison of the spectrum of the epoxy prepreg with that of DGEBA shows no change in the band shape and position for the epoxy and hydroxyl absorptions. The peaks observed for different functional groups were assigned according to the reported values in the literature $1,19,20,27$ and are listed in Table I. In the epoxy prepreg, besides the characteristic peaks of DGEBA, small absorption bands at 4930, 4980, and $5044 \mathrm{~cm}^{-1}$ were detected. These peaks were also found in the spectrum of DICY. ${ }^{29}$ In the reported values for primary amine absorption in the NIR range, the peak around $5044 \mathrm{~cm}^{-1}$ is the combination band of the aromatic primary amine, and the $4930 \mathrm{~cm}^{-1}$ is absorption by the aliphatic primary amine. ${ }^{30}$ Figure 2 shows the NIR spectra of the epoxy prepreg for different

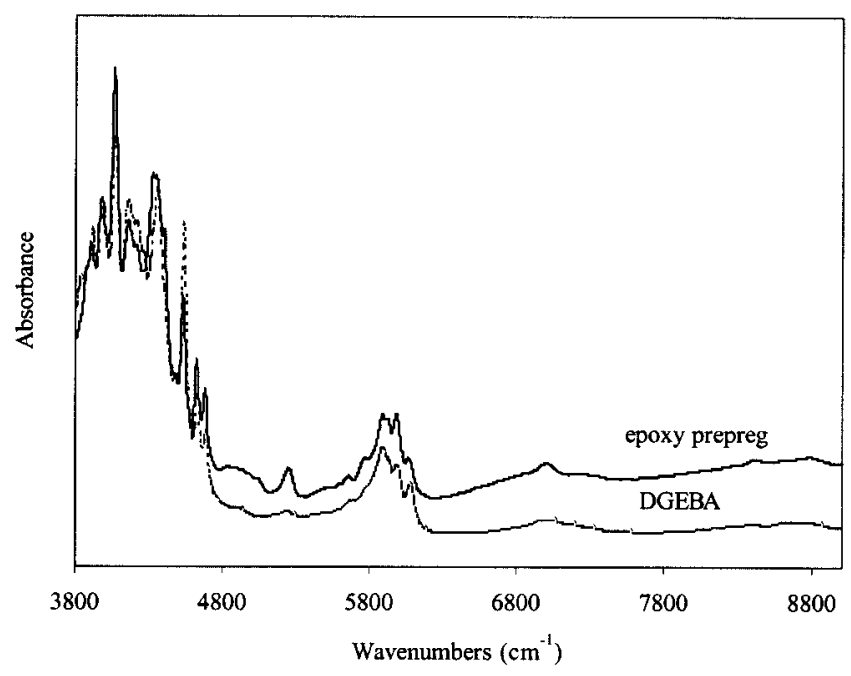

Figure 1 NIR spectra of the epoxy prepreg and DGEBA at room temperature. 
TABLE I

Assignment of the Observed Peaks for the Different Chemical Groups in the Epoxy Prepreg

\begin{tabular}{lcc}
\hline \multicolumn{1}{c}{ Chemical group } & $\begin{array}{c}\text { Peak position } \\
\left(\mathrm{cm}^{-1}\right)\end{array}$ & $\begin{array}{c}\text { Integration range } \\
\left(\mathrm{cm}^{-1}\right)\end{array}$ \\
\hline Aromatic C-H & 4064,4680 & \\
& 4622 & $4652-4590$ \\
Epoxy C-H & 5985 & $6041-5952$ \\
& 4529 & $4497.7-4555.5$ \\
Primary amine N-H & 6066 & \\
Absorbed water & 4930 & $5068-5022$ \\
Hydroxyl O-H & 5044 & $5319-5134$ \\
& 5247 & $7117-6858$ \\
\hline
\end{tabular}

curing times at $90^{\circ} \mathrm{C}$. The enlarged spectra in the DICY absorption range of the epoxy prepreg are shown in Figure 3. Because during the reaction the formation of the hydroxyl group increased, the absorption around $4795 \mathrm{~cm}^{-1}$ and the baseline shifted up, and this might have caused interference with the peaks at 4930 and $4980 \mathrm{~cm}^{-1}$, so only the peak at $5044 \mathrm{~cm}^{-1}$ was monitored. The peak at $5247 \mathrm{~cm}^{-1}$ was the absorption by absorbed water in the epoxy prepreg. ${ }^{21,31}$

\section{Calculation of the conversions}

The spectra were normalized at the $4622 \mathrm{~cm}^{-1}$ aromatic $\mathrm{C}-\mathrm{H}$ combination band. The changes in the epoxy, primary amine, water, and hydroxyl groups were calculated by the integration of the peaks at 4529 , 5044, 5247, and $7000 \mathrm{~cm}^{-1}$, respectively, at defined wave-number ranges, as shown in Table I. All the samples had slightly different thicknesses, and the thickness of a sample might change during the curing; to compensate for the change in thickness, an internal standard was needed. The absorption band of aromatic $\mathrm{C}-\mathrm{H}$ at $4622 \mathrm{~cm}^{-1}$ was used as an internal

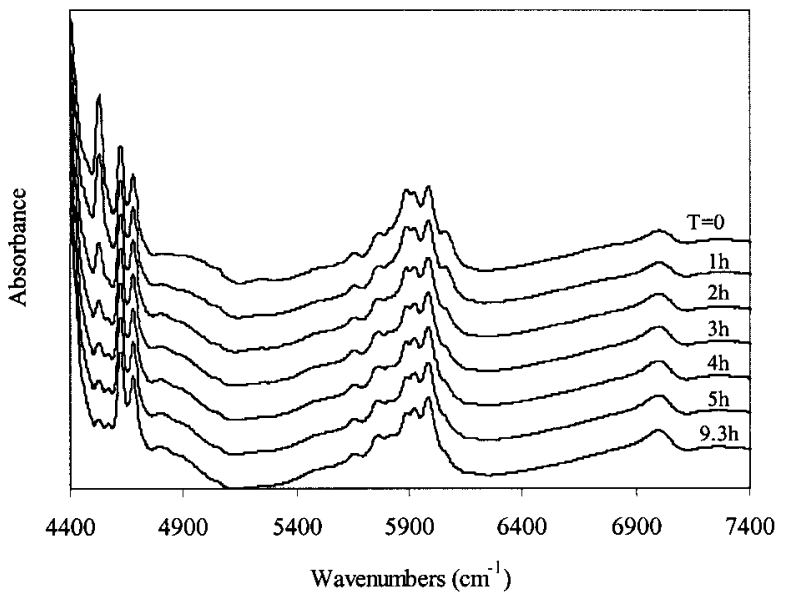

Figure 2 NIR spectra of the epoxy prepreg cured at $90^{\circ} \mathrm{C}$ for different times.

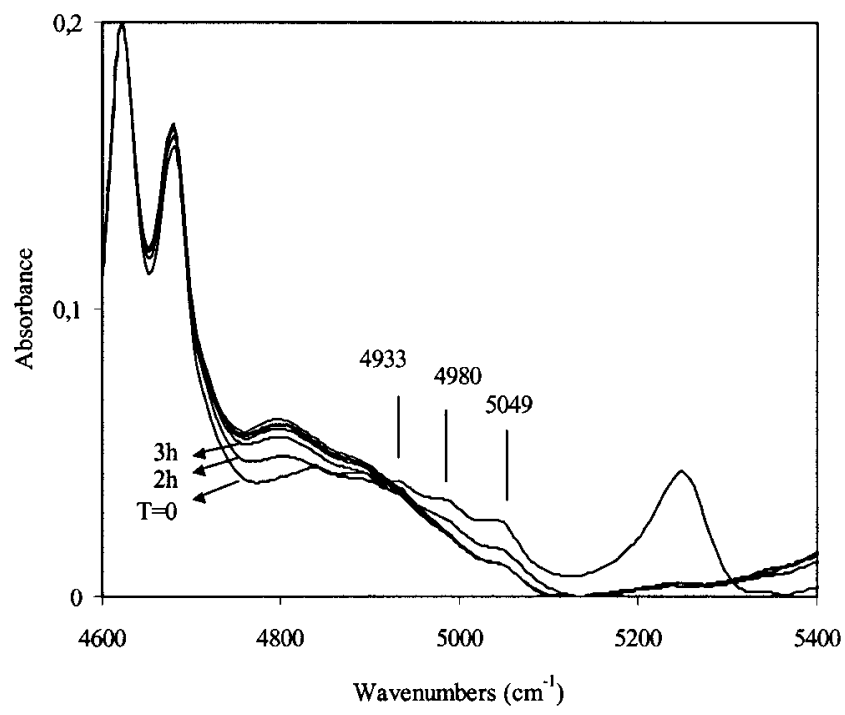

Figure 3 Enlarged NIR spectra of the epoxy prepreg cured at $90^{\circ} \mathrm{C}$ for different times.

standard for the epoxy, primary amine group, and water. The epoxy group conversion $\alpha_{E}$ was calculated as follows:

$$
\alpha_{E}=\left(1-\frac{H_{E t} / H_{r t}}{H_{E 0} / H_{r 0}}\right) \times 100 \%
$$

where $H_{E t}$ and $H_{r t}$ are the band intensities of the epoxy and aromatic reference peaks at curing time $t$ in the normalized spectrum, respectively, and $H_{E 0}$ and $H_{r 0}$ are the initial absorbances at time 0 . $^{*}$

The conversion of the primary amine group and the change in the water content were calculated by the same equation with the same internal standard, but the normalized absorption areas were used instead of the band height.

If the cure reaction shown in Scheme 2 is the main reaction, it can be assumed that only the amine-epoxy addition will form hydroxyl groups; therefore, the hydroxyl production percentage is calculated under the assumption that the initial DICY concentration is the total number of hydroxyl groups that can be

\footnotetext{
*Both the band intensity and band area were used for the calculation of the epoxy conversion in the same integration range. A relatively larger epoxy conversion was obtained with the band area in the calculation. In the second method, a curve-fitting program, with peaks assumed to be Gaussian in shape, was used for the integration of the band intensity and area. The second method showed the same tendency as the first method for the epoxy conversion calculated by the band intensity and area; however, the epoxy conversion calculated by the band area with values from the curve fitting was equal to that calculated by the band intensity in the former method. Therefore, the band intensity was used to calculate the epoxy conversion in this study.
} 


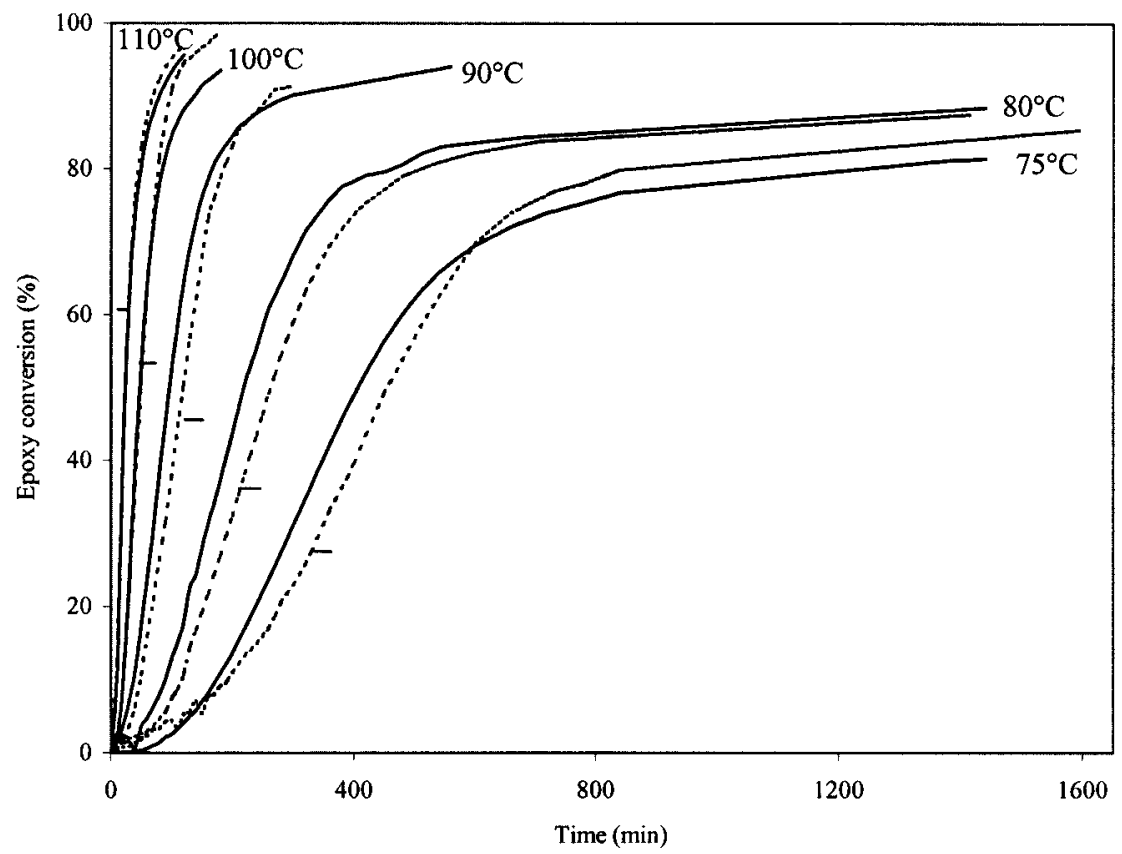

Figure 4 Epoxy conversion versus time at different cure temperatures under condition 1 (solid lines, from 75 to $110^{\circ} \mathrm{C}$ ) and condition 2 (dashed lines, from 75 to $110^{\circ} \mathrm{C}$; the small marks on the dashed lines indicate at which point the light transmittance of the sample started to decrease).

formed. With the aromatic $\mathrm{C}-\mathrm{H}$ absorption at 5985 $\mathrm{cm}^{-1}$ used as an internal standard, the hydroxyl production $\left(\alpha_{\mathrm{OH}}\right)$ was calculated as follows:

$$
\alpha_{\mathrm{OH}}=\left(\frac{A_{\mathrm{OH} t} / A_{r t}-A_{\mathrm{OH} 0} / A_{r 0}}{A_{\mathrm{DICY} 0} / A_{r 0}}\right) \times B \times 100 \%
$$

where

$$
B=\frac{\varepsilon_{\mathrm{DICY}}}{f \times \varepsilon_{\mathrm{OH}}}
$$

The normalized band areas were integrated and used in the calculation. The hydroxyl group production obtained by eq. (2) was only a relative value and was not correlated to the epoxy conversion because of the lack of knowledge of the molar extinction coefficients of the hydroxyl group $\left(\epsilon_{\mathrm{OH}}\right)$ and primary amine group $\left(\epsilon_{\text {DICY }}\right)$ and the functionality of DICY $(f)$. The constant $B$, equal to 1 , was used in the calculation.

For confirmation that no significant difference would occur with different aromatic $\mathrm{C}-\mathrm{H}$ bands as internal standards, that is, bands at 4622 and 5985 $\mathrm{cm}^{-1}$, the ratio of the band area and the band intensity of these two peaks was calculated with the NIR spectra obtained at different stages of cure, and it was found that the ratio did not change significantly during the curing at different temperatures.

\section{RESULTS AND DISCUSSION}

\section{Changes in the functional groups under the two cure conditions}

Epoxy conversion at different temperatures

Figure 4 shows the epoxy conversion during the curing at different temperatures. Under both curing conditions, the epoxy conversion increased with increasing cure temperature but leveled off without reaching $100 \%$, even for prolonged curing times with curing at low temperatures of $75-80^{\circ} \mathrm{C}$. According to a comparison of the curve at $80^{\circ} \mathrm{C}$ with that reported for a similar epoxy system, ${ }^{29}$ the epoxy conversion rate in this study was higher at the initial epoxy conversion stage, but the final epoxy conversion degree was the same. The lack of an induction phase in the curing of the epoxy prepreg might have been due to the partial reaction of the prepreg during its preparation process or the difference in the initial proportions of the different components in the reaction system.

During the curing, the light transmittance of the sample increased at the beginning because of the decreased viscosity of the epoxy resin upon heating and the reaction of DICY and diuron. The light transmittance then started to decrease gradually because of the epoxy network formation. Despite the different cure temperatures, the light transmittance of the sample always started to decrease at about $40 \%$ epoxy conversion with curing under condition 1 . In a highperformance liquid chromatography study of a similar 
epoxy system, the gel times for the samples cured under isothermal conditions at different temperatures always appeared at $40 \%$ epoxy conversion, ${ }^{15}$ and this agreed with our observations. It also implies that the epoxy conversion degree at which the light transmittance started to decrease is related to the gel point of the epoxy prepreg in this study. However, when the samples were cured under condition 2, the gel point (the decrease in the light transmittance) was different at different cure temperatures and appeared at higher epoxy conversion degrees at high cure temperature, as shown in Figure 4.

Besides the difference in the gel point, it was observed that when the sample was cured under condition 1, the initial reaction rate was larger but the final epoxy conversion degree was generally lower than under condition 2 at the same cure temperature.

\section{Primary amine conversion}

Figure 5 shows the primary amine conversion (at 5044 $\mathrm{cm}^{-1}$ ) versus the epoxy conversion at different cure temperatures. It is clear that the primary amine conversion increased with an increasing cure temperature. The amine conversion was only $80 \%$, even when the sample was cured at $110^{\circ} \mathrm{C}$ under condition 1 , and this indicates that there was still some DICY left in the cured epoxy prepreg. A very low amine conversion observed at low cure temperatures $\left(<90^{\circ} \mathrm{C}\right)$ could be explained by the low solubility of DICY in the epoxy resin at low temperatures; another reason was that more cyanamide produced during the reaction dimerized into DICY at low cure temperatures. However, when the samples were cured under condition 2 at 75 or $80^{\circ} \mathrm{C}$, a larger amount of DICY was consumed in the reaction. The same tendency was found for the

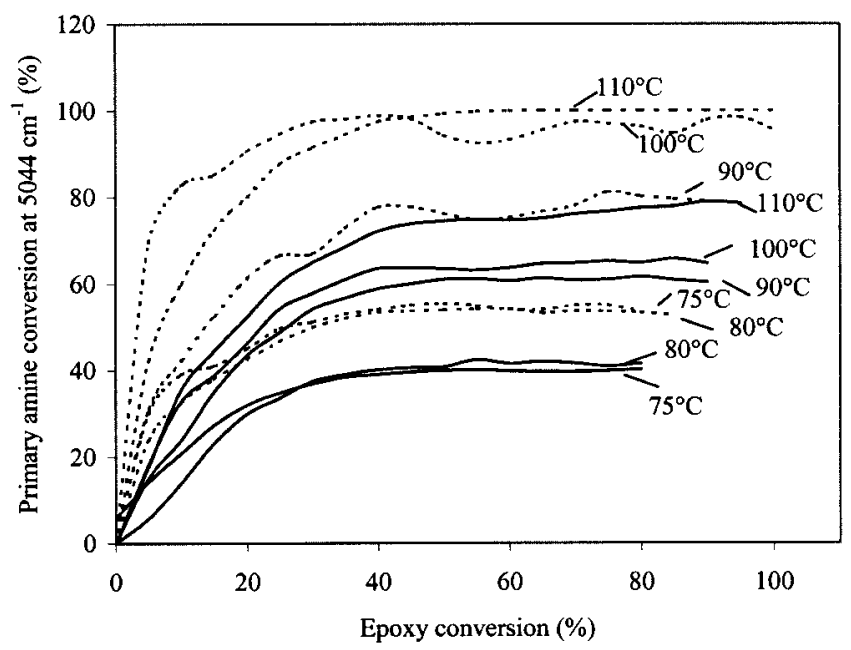

Figure 5 Primary amine conversion versus the epoxy conversion at different cure temperatures under condition 1 (solid lines) and condition 2 (dashed lines).

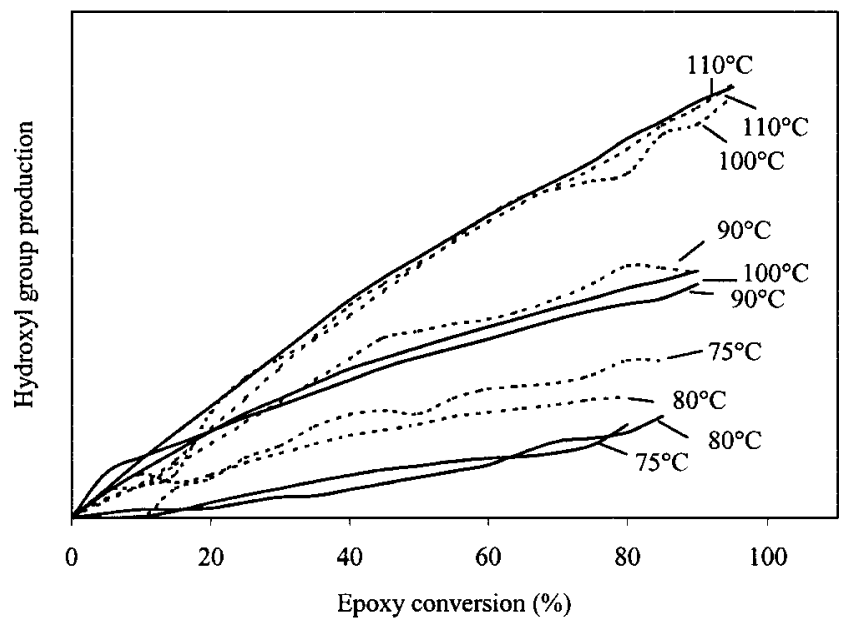

Figure 6 Hydroxyl group production versus the epoxy conversion in the cure of the epoxy prepreg at different temperatures under condition 1 (solid lines) and condition 2 (dashed lines).

samples cured at high temperatures $\left(90-110^{\circ} \mathrm{C}\right)$ under condition 2. These results suggest that DICY and epoxy reacted more under condition 2 .

\section{Hydroxyl production}

The hydroxyl production versus the epoxy conversion during the cure is shown in Figure 6. Because each amine-epoxy addition can form one hydroxyl group, the higher the primary amine conversion is in Figure 5 , the higher the hydroxyl group production is in Figure 6. Generally, a larger amount of the hydroxyl group was formed under condition 2 than under condition 1 because of the higher DICY conversion. The higher hydroxyl production for the sample cured at $110^{\circ} \mathrm{C}$ under condition 1 was probably due to the greater secondary amine-epoxy reaction in the sample.

\section{Water desorption}

When epoxy is cured in the presence of a tertiary amine, a synergetic effect causes the reaction rate to be higher than that for either pure epoxy-amine addition or epoxy homopolymerization (or etherification). Zahir ${ }^{4}$ proposed that the cured product of epoxy and DICY accelerated by dimethylbenzylamine had a chemical structure generated from both epoxy-amine addition and etherification. An isothermal DSC study by Schneider et al. ${ }^{10}$ on the cure of two epoxy /DICY/ uron systems suggested that the reactions of epoxy with amine and hydroxyl occurred with a similar activation energy $(83.6 \mathrm{~kJ} / \mathrm{mol})$ that was higher than that of the pure epoxy-amine addition $(50 \mathrm{~kJ} / \mathrm{mol})$. These results imply that the reaction mechanism is a combination of epoxy-amine addition and epoxy homopo- 


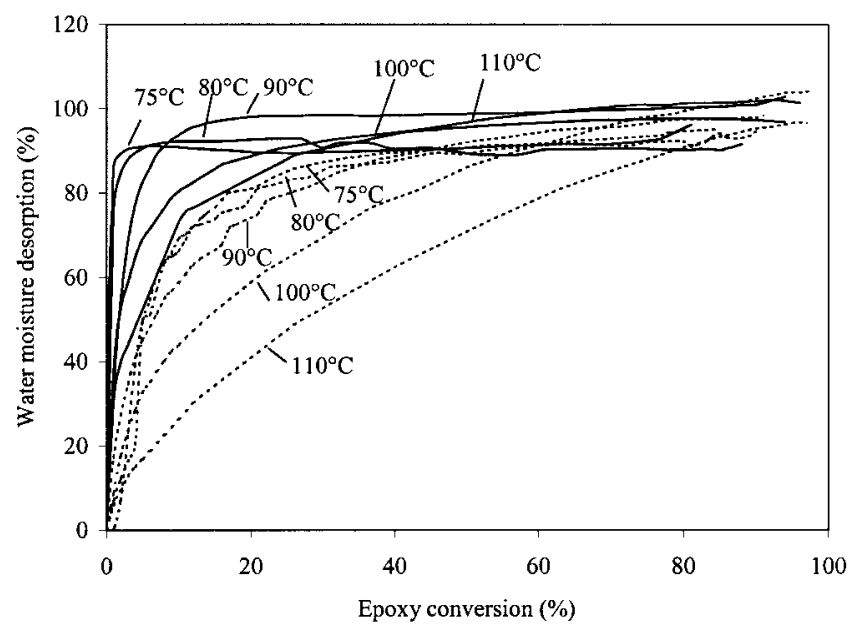

Figure 7 Absorbed water desorption versus the epoxy conversion for the epoxy prepreg cured at different temperatures under condition 1 (solid lines) and condition 2 (dashed lines).

lymerization and that the tertiary amine produced by the decomposition of the diuron accelerator plays an important role in catalyzing both reactions. ${ }^{4,7}$ In this study, the changes in the epoxy, primary amine, and hydroxyl groups under the two cure conditions show that more primary amine-epoxy addition occurred during the early stage of cure, but the cure rate decreased under condition 2. Because a proton donor is generally involved in the reaction mechanism in epoxy reactions, as shown in Scheme 1, a plot of the desorption of water against the epoxy conversion during the cure under the two conditions was studied, as shown in Figure 7. The release of the absorbed water was faster when the sample was cured directly than when it was cured between two glass plates (condition 2). Under both cure conditions, more epoxy was consumed before all the water was released at higher cure temperatures. Water is a proton donor that can form a hydrogen-bonding complex with the epoxy group to activate the oxirane ring and make a positive effect on the epoxy consumption, but it can also form a complex with tertiary amine to reduce the activity, resulting in a low curing rate. Therefore, during the early stage of cure, more epoxy reacted with the highly activated amino hydrogen in DICY, and more of the cyclization product, 2-amino-2-oxazoline, was produced. 2-Amino-2-oxazoline, which is a base that further catalyzes epoxy-amine addition and homopolymerization, is supposed to be deactivated to some extent by water during the early stage, also leading, therefore, to a low curing rate.

In addition, it was reported that amino-oxazoline could be hydrolyzed by water in the presence of a $50 \%$ $\mathrm{NaOH}$ solution. ${ }^{7}$ It is then supposed that amino-oxazoline serves as a strong base itself ${ }^{4}$ and can be broken down in the presence of water, especially at high temperatures. Because the dissociation of the oxazoline ring will reduce the molecular weight and crosslinking of the epoxy network, the gel point will appear at a higher epoxy conversion degree. The higher the cure temperature is, the more dissociation there is and the later the gel point occurs, as shown in Figure 4 . The higher epoxy conversion degree for samples cured under condition 2 can tentatively be explained as follows. Because the gel point appeared at a higher epoxy conversion degree, the diffusion-controlled reaction occurred at a higher epoxy conversion degree and enabled a large total epoxy conversion. For the sample cured at $75^{\circ} \mathrm{C}$, more DICY was integrated into the epoxy reaction product and caused more crosslinking. The dissociation was not strong at this low temperature, and so the lowest gel point was observed. The higher final epoxy conversion degree at this temperature under condition 2 may be due to the higher DICY conversion in the polymer.

\section{Activation energy under the two cure conditions}

Figure 8(a) shows the decrease in the epoxy group during the curing. The data are expressed in terms of the peak intensity ratios of the epoxy group to the aromatic absorption at $4622 \mathrm{~cm}^{-1}$ [R(Epo/Ar)]. The first derivative of the curve was calculated to obtain a plot of the relative epoxy conversion rate versus time, as shown in Figure 8(b). Both of the curves demonstrate an autocatalysis mechanism for the epoxy conversion.

The study of Hagnauer ${ }^{15}$ on the cure of an Epon $828 / \mathrm{DICY} /$ monuron system, which was similar to the epoxy prepreg, showed that in the early stages of the reaction, the rate of reaction of the epoxy group $(r)$ follows first-order kinetics:

$$
r=\frac{d C_{E}}{d t}=k C_{E}
$$

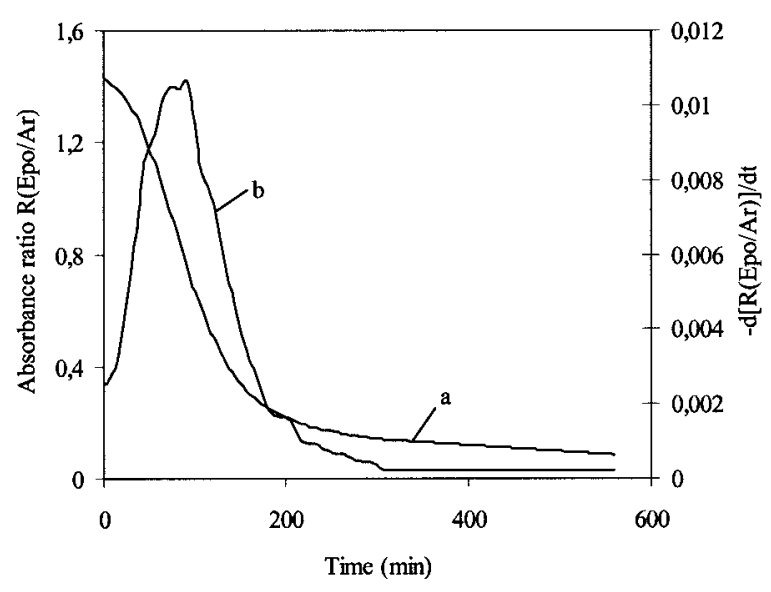

Figure 8 (a) Absorbance ratio versus time and (b) relative epoxy conversion rate versus time for the epoxy prepreg cured at $90^{\circ} \mathrm{C}$. 


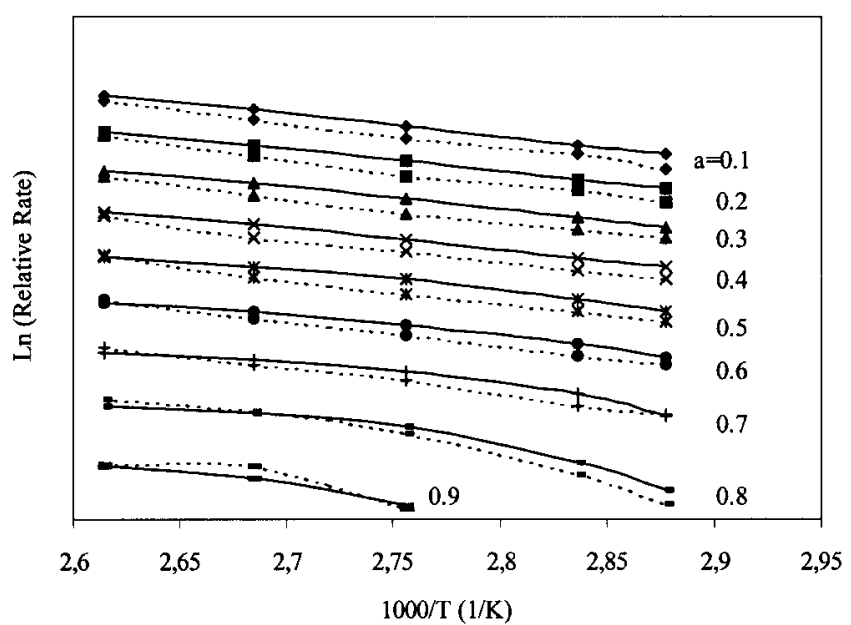

Figure 9 Natural logarithm of the relative rate against $1 / T$ for the epoxy prepreg under condition 1 (solid lines) and condition 2 (dashed lines). The epoxy conversion degree $\alpha$ from 10 to $90 \%$ is displayed along the curves. The curves have been displaced vertically for clarity.

where $C_{E}$ is the epoxy concentration and $k$ is the reaction constant. Equation (3) can be transformed with the application of the normal Arrhenius form:

$$
\ln \left(\frac{r_{1}}{r_{2}}\right)=\frac{E}{R} \times\left(\frac{1}{T_{2}}-\frac{1}{T_{1}}\right)
$$

where $r_{1} / r_{2}$ is the ratio of the rates of epoxy consumption at cure temperatures $T_{1}$ and $T_{2}$, respectively. By the plotting of $\ln \left(r_{1} / r_{2}\right)$ versus the reciprocal of the temperature $(1 / T)$, the activation energy $E$ was obtained from the resulting straight line. In this study, $r_{1} / r_{2}$ was replaced by $-d[R(\mathrm{Epo} / \mathrm{Ar})] / d t$ from Figure 8 (b) because this displacement did not change the final activation energy value.

The apparent activation energy under the two cure conditions was further studied and compared at different epoxy conversion stages. Figure 9 shows that under condition 1 during early stages of cure (up to $40 \%$ epoxy conversion), the change in the natural logarithm of the relative rate was almost linear and that the activation energy $(93.5-86.6 \mathrm{~kJ} / \mathrm{mol})$ agreed well with those values determined with DSC and TBA (torsional braid analysis). ${ }^{10,32}$ Because of the low solubility of DICY in the epoxy resin below $90^{\circ} \mathrm{C}$, the same gel point for the samples cured under condition 1 suggests that during the early stage of cure, a similar reaction mechanism was at work, and the reaction product was a combination of both epoxy-amine addition and epoxy polymerization, as shown in Scheme 2.

After $40 \%$ epoxy conversion under condition 1, two different rate patterns were observed. The rate decreased quickly in the low-cure-temperature range $\left(75-80^{\circ} \mathrm{C}\right)$ at higher epoxy conversion degrees, and this was due to the diffusion-controlled reaction and limited DICY solubility in the reaction mixture. In the high-cure-temperature range $\left(90-110^{\circ} \mathrm{C}\right)$, the activation energy $\left(E_{1}\right)$ decreased at higher epoxy conversion degrees (Table II) and was close to the activation energy of the epoxy-amine addition reaction. ${ }^{9}$ This suggests that at higher epoxy conversion stages, the dominant reaction was an epoxy-amine addition reaction. Because DICY could dissolve well in the epoxy resin at $90^{\circ} \mathrm{C}$, and the epoxy polymerization rate decreased at a higher epoxy conversion degree, ${ }^{2}$ it is understandable that the epoxy-amine addition became the main reaction.

In Figure 9, we can see that the two rate patterns were not obvious under cure condition 2 and that the activation energy was larger $\left(E_{3}>E_{2}\right.$; Table II). Together with the differences in the changes in the functional groups, the large difference in the activation energy for the two cure conditions indicates that the reaction underwent different reaction mechanisms and implies some differences in the final epoxy network structure.

\section{DSC study of the cured sample}

DSC scans from 25 to $230^{\circ} \mathrm{C}$ were performed on the samples after curing under condition 1 , and curetemperature-dependent $T_{g}$ 's were observed (Fig. 10). $T_{g}$ increased with the cure temperature, and this was also reported in Oleinik's work. ${ }^{33}$ Small endothermic peaks at $211^{\circ} \mathrm{C}$ in the cured samples were obvious and close to the melting point of DICY $\left(210^{\circ} \mathrm{C}\right)$, and this indicates that some DICY remained in the cured epoxy prepreg. In Figure 10, the increase in the heat capacity after $T_{g}$ indicated that the residual epoxy group was undergoing a further reaction. The samples were then cooled to room temperature, and another scan was started (Fig. 11). In the second scan, $T_{g}{ }^{\prime}$ s for the samples cured at 80 and $90^{\circ} \mathrm{C}$ were slightly larger but still close to those of the samples cured at other temperatures. This result generally agrees with the discussion

TABLE II

Apparent Activation Energy of the Epoxy Prepreg Cured at Conditions 1 and 2

\begin{tabular}{cccc}
\hline$\alpha$ & $E_{1}(\mathrm{~kJ} / \mathrm{mol})^{\mathrm{a}}$ & $E_{2}(\mathrm{~kJ} / \mathrm{mol})^{\mathrm{b}}$ & $E_{3}(\mathrm{~kJ} / \mathrm{mol})^{\mathrm{c}}$ \\
\hline 0.1 & 91.7 & 93.5 & 104.2 \\
0.2 & 89.6 & 90.9 & 103.1 \\
0.3 & 82.9 & 89.2 & 97.9 \\
0.4 & 76.2 & 86.6 & 96.9 \\
0.5 & 63.1 & 84.1 & 101.2 \\
0.6 & 63.5 & 85.8 & 102.2 \\
0.7 & 55.0 & 96.9 & 107.5 \\
0.8 & 57.4 & & \\
\hline
\end{tabular}

\footnotetext{
a Samples cured between 90 and $110^{\circ} \mathrm{C}$ (condition 1).

${ }^{b}$ Samples cured between 75 and $110^{\circ} \mathrm{C}$ (condition 1).

${ }^{c}$ Samples cured between 75 and $100^{\circ} \mathrm{C}$ (condition 2).
} 


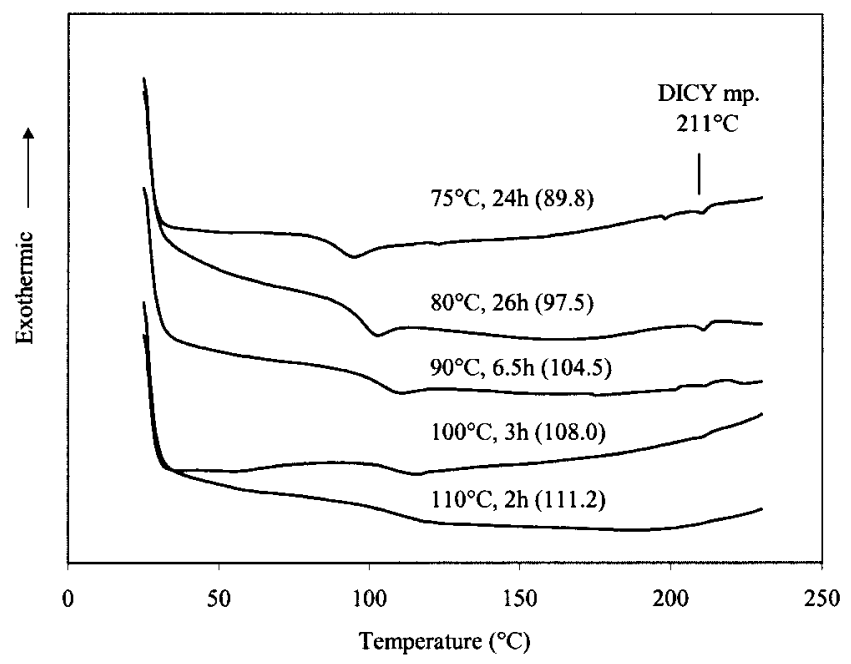

Figure 10 First DSC scan of the epoxy prepreg after curing at different temperatures and for different cure times under condition 1 . The values in parentheses are $T_{g}$ 's. The heating rate was $10^{\circ} \mathrm{C} / \mathrm{min}$.

in the papers ${ }^{2-4}$ that after the postcuring of the isothermally precured samples, the preheating history disappears and the relaxation of the nonequilibrated structures frozen at the cure temperature occurs. The small endothermic peak at $260^{\circ} \mathrm{C}$ in the degradation temperature range observed for all the samples in Figure 11 is still not assigned yet; it may be due to the same derivatives formed from DICY. The DSC results, together with the same gel points, suggest that when the epoxy prepreg was cured under condition 1, the same reaction mechanism applied and the epoxy network formed after postcuring was similar, with only slightly higher $T_{g}$ 's for the samples cured at $80-90^{\circ} \mathrm{C}$.

The same DSC study was performed on the samples cured under condition 2 . The samples showed the

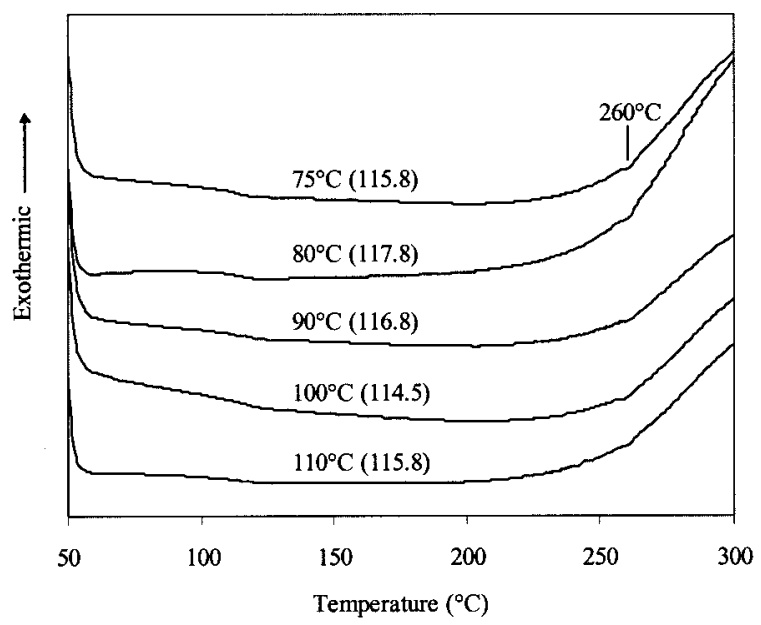

Figure 11 DSC scans of the epoxy prepreg cured under condition 1 at different temperatures after the first scan. The values in parentheses are $T_{g}^{\prime}$ s. The heating rate was $10^{\circ} \mathrm{C} /$ min. same isothermal-conversion-dependent $T_{g}$ as those cured under condition 1 . In Table III, $T_{g}$ 's of the cured epoxy prepreg under the two cure conditions are compared. From the $T_{g}$ values obtained in the first DSC scan, the samples cured between two glass plates (condition 2) had larger $T_{g}$ 's than those cured directly in the glass vial (condition 1); this is consistent with the higher epoxy conversion degree obtained under condition 2. However, when the samples were scanned again, $T_{g}$ 's of the samples cured under condition 2 were lower than those of samples cured under condition 1. Together with the NIR results on different functional group conversions, this implies that the samples underwent different reaction mechanisms and that the final epoxy network was different under the two cure conditions. Under condition 2, more epoxy-amine addition occurred, and the dissociation of the oxazoline ring during the reaction might have resulted in small crosslinking domains in the composites and a lack of a large density of crosslinking points. Without regard for the differences in $T_{g}$ 's for the samples cured at different conditions, however, a similar $T_{g}$ tendency was observed: the samples cured at 80 and $90^{\circ} \mathrm{C}$ had slightly higher $T_{g}$ 's than the others, and this suggests that the final epoxy network structure depended on the preheating history to some extent when the postcuring was performed at high temperatures.

\section{FTIR spectra of the samples cured under condition 1}

The FTIR spectra of the cured samples are quite similar, as shown in Figure 12. The remaining epoxy group appeared as a small shoulder at $915 \mathrm{~cm}^{-1}$ in the low-temperature-cured samples. The interference of glass fibers from 850 to $1150 \mathrm{~cm}^{-1}$ made it impossible to monitor the reaction by FTIR. The peak at 1760 $\mathrm{cm}^{-1}$ was assigned to the carbonyl absorption of the

TABLE III

$T_{g}$ for the Cured Epoxy Prepreg Cured under Different Conditions

\begin{tabular}{lrrrrr}
\hline & \multicolumn{5}{c}{ Cure temperature $\left({ }^{\circ} \mathrm{C}\right)$} \\
\cline { 2 - 6 } & \multicolumn{1}{c}{75} & \multicolumn{1}{c}{80} & 90 & 100 & 110 \\
\hline$T_{g}{ }^{a}(1)\left({ }^{\circ} \mathrm{C}\right)$ & 89.8 & 97.5 & 104.5 & 108.0 & 111.2 \\
$T_{g}^{a}(2)\left({ }^{\circ} \mathrm{C}\right)$ & 92.9 & 98.0 & 105.6 & 108.4 & 110.1 \\
$T_{g} \mathrm{~b}(1)\left({ }^{\circ} \mathrm{C}\right)$ & 115.8 & 117.8 & 116.8 & 114.5 & 115.8 \\
$T_{g} \mathrm{~b}(2)\left({ }^{\circ} \mathrm{C}\right)$ & 113.0 & 114.0 & 113.4 & 109.8 & 110.4 \\
\hline
\end{tabular}

${ }^{\text {a }}$ The $T_{g}$ was obtained on the first DSC scan of the cured sample. The DSC condition was the same as in Figure 10. The number in parentheses indicates that the sample was cured under condition 1 or 2 .

b The $T_{g}$ was obtained on the second DSC scan of the cured sample. The DSC condition was the same as in Figure 11. The number in parentheses indicates that the sample was cured under condition 1 or 2 . 


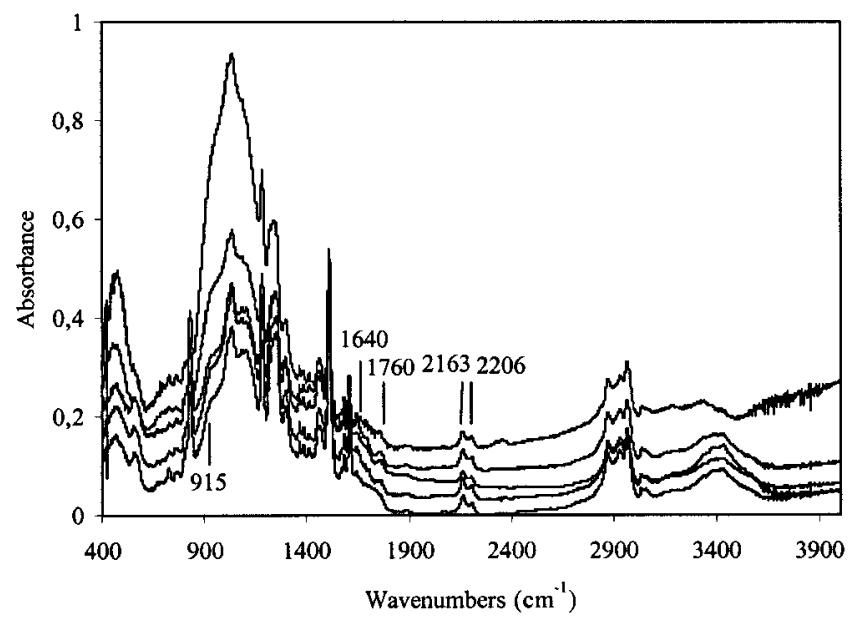

Figure 12 FTIR spectra of the epoxy prepreg after curing at different temperatures. The spectra from the bottom to the top are for the samples cured at $75(24 \mathrm{~h}), 80(26 \mathrm{~h}), 90$ (6.5

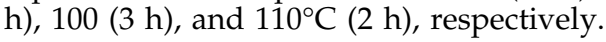

reaction product of diuron with epoxy, oxazolidin-2one, as reported by Bryne et al. ${ }^{6}$ Its intensity increased with the increasing cure temperature, so that more diuron reacted with epoxy at a high cure temperature and more tertiary amine formed to catalyze the cure reaction. The absorption peak at $1640 \mathrm{~cm}^{-1}$ was assigned to the imine absorption in the DICY-epoxy addition product amino-2-oxazoline. No big difference in intensity was observed for the samples cured at different temperatures. The broad band centered at $3380 \mathrm{~cm}^{-1}$ was assigned to the secondary amine absorption. The sample cured at $110^{\circ} \mathrm{C}$ had a small absorption in this range, and this indicates that most of the secondary amine reacted.

\section{CONCLUSIONS}

We studied the isothermal cure of the epoxy prepreg under two conditions by NIR. The results indicate that when the sample was cured at low temperatures (75$80^{\circ} \mathrm{C}$ ), the epoxy did not reach $100 \%$ conversion at prolonged curing times because of the diffusion-controlled reaction phase and because of the limited DICY solubility. When the samples were cured directly, similar gel points and $T_{g}{ }^{\prime}$ s (after postcuring by DSC) were observed, and this indicates that the reaction mechanism under condition 1 was the same at different temperatures. The study of the activation energy showed that at a high epoxy conversion (70\%), the dominant reaction was epoxy-amine addition (92-55 $\mathrm{kJ} / \mathrm{mol}$ ) at high cure temperatures $\left(90-110^{\circ} \mathrm{C}\right)$. When the samples were cured between two glass plates, a lower initial epoxy conversion rate and a higher final epoxy conversion were observed. The study on the primary amine conversion and hydroxyl group production under condition 2 indicated that more epoxy groups were consumed by epoxy-amine addition. The absorbed water in the samples was assumed to have a significant effect on both reducing the activity of the active species and hydrolyzing the amine-epoxy addition product. The activation energy was larger under this cure condition $(104-97 \mathrm{~kJ} / \mathrm{mol})$, and $T_{g}$ 's of the cured samples were lower that those of the samples cured at condition 1.

The authors thank Milosz A. Gwizdalski for preparing the samples for the NIR study and for running the DSC analysis.

\section{References}

1. Xu, L.; Fu, J. H.; Schlup, J. R. J Am Chem Soc 1994, 116, 2821

2. Rozenberg, B. A. Adv Polym Sci 1985, 75, 113.

3. Lee, J. Y.; Choi, H. K.; Shim, M. J.; Kim, S. W. Thermochim Acta 2000, 344, 111.

4. Zahir, S. A. Adv Org Coat Technol 1983, 4, 83.

5. LaLiberte, B. R.; Bornstein, J.; Sacher, R. E. Ind Eng Chem Prod Res Dev 1983, 22, 261.

6. Bryne, C. A.; Hagnauer, G. L.; Schneider, N. S. Polym Compos 1983, 4, 206.

7. Barwich, J.; Guse, D.; Brockmann, H. Adhesion 1989, 5, 27.

8. Sacher, E. Polymer 1973, 14, 91.

9. Barton, J. M. Adv Polym Sci 1985, 72, 111.

10. Schneider, N. S.; Sprouse, J. F.; Hagnauer, G. L.; Gillham, J. K. Polym Eng Sci 1979, 19, 304.

11. Poisson, N.; Maazouz, A.; Sautereau, H.; Taha, H.; Gambert, X. J Appl Polym Sci 1998, 69, 2487.

12. Amdouni, N.; Sautereau, H.; Gérard, J.-F.; Pascault, J.-P. Polymer 1990, 31, 1245.

13. Güthner, T.; Hammer, B. J Appl Polym Sci 1993, 50, 1453.

14. Saunders, T. F.; Levy, M. F.; Serino, J. F. J Polym Sci Part A-1: Polym Chem 1967, 5, 1609.

15. Hagnauer, G. L. Proceedings of Critical Review-Characterization of Composite Materials, Cambridge, MA, June 8-10, 1981; p 3.

16. Abolafia, O. R. Soc Plast Eng Annu Tech Conf Proc 1969, 15, 610.

17. Lachenal, G.; Pierre, A.; Poisson, N. Micron 1996, 27, 329.

18. Dannenberg, H. Soc Plast Eng Trans 1963, 3, 78.

19. Strehmel, V.; Scherzer, T. Eur Polym J 1994, 30, 361.

20. George, G. A.; Cole-Clarke, P.; St. John, N.; Friend, G. J Appl Polym Sci 1991, 42, 643.

21. Musto, P.; Martuscelli, E.; Ragosta, G.; Russo, P. High Perform Polym 2000, 12, 155.

22. Varley, R. J.; Heath, G. R.; Hawthorne, D. G.; Hodgkin, J. H.; Simon, G. P. Polymer 1995, 36, 1347.

23. Min, B.-G.; Stachurski, Z. H.; Hodgkin, J. H.; Heath, G. R. Polymer 1993, 34, 3620.

24. Mijović, J.; Andjelić, S.; Winnie Yee, C. F.; Bellucci, F.; Nicolais, L. Macromolecules 1995, 28, 2797.

25. DeBakker, C. J.; George, G. A.; John, N. A. S. Spectrochim Acta A $1993,49,739$

26. Mijović, J.; Fishbain, A.; Wijaya, J. Macromolecules 1992, 25, 979.

27. Mijović, J.; Andjelić, S. Macromolecules 1995, 28, 2787.

28. St. John, N. A.; George, G. A. Polymer 1992, 33, 2679.

29. Poisson, N.; Lachenal, G.; Sautereau, H. Vib Spectrosc 1996, 12, 237.

30. Johnson, F. J.; Cross, W. M.; Boyles, D. A.; Kellar, J. J. Compos A 2000, 31, 959.

31. Min, B.-G.; Shin, D.-K.; Stachurski, Z. H.; Hodgkin, J. H. Polym Bull 1994, 33, 465.

32. Schneider, N. S.; Gillham, J. K. Polym Compos 1980, 1, 97.

33. Oleinik, E. F. Pure Appl Chem 1981, 53, 1567. 